Cite this article as: BMJ, doi:10.1136/bmj.38243.672396.55 (published 22 October 2004)

\title{
Papers
}

\section{Paternal age and schizophrenia: a population based cohort study}

\author{
Attila Sipos, Finn Rasmussen, Glynn Harrison, Per Tynelius, Glyn Lewis, David A Leon, David Gunnell
}

\begin{abstract}
Objective To investigate the association of paternal age at conception with the risk of offspring developing schizophrenia. Design A population based cohort study.

Setting Sweden.

Subjects 754330 people born in Sweden between 1973 and 1980 and still alive and resident in Sweden at age 16 years.

Main outcome measures Hospital admission with schizophrenia or non-schizophrenic, non-affective psychosis. Results After adjustment for birth related exposures, socioeconomic factors, family history of psychosis, and early parental death the overall hazard ratio for each 10 year increase in paternal age was 1.47 (95\% confidence interval 1.23 to 1.76$)$ for schizophrenia and 1.12 (0.98 to 1.29) for non-schizophrenic non-affective psychosis. This association between paternal age and schizophrenia was present in those with no family history of the disorder (hazard ratio for each 10 year increase in paternal age $1.60,1.32$ to 1.92$)$, but not in those with a family history (0.91, 0.44 to 1.89$)(\mathrm{P}=0.04$ for interaction).

Conclusions Advancing paternal age is an important independent risk factor for schizophrenia. The stronger association between paternal age and schizophrenia in people without a family history provides further evidence that accumulation of de novo mutations in paternal sperm contributes to the overall risk of schizophrenia.
\end{abstract}

\section{Introduction}

There is growing evidence that factors operating at different points in life contribute to an individual's risk of developing schizophrenia. Recent research interest has focused on the influence of paternal age at conception..$^{1-6}$ Advancing paternal age is known to be associated with several other disorders, ${ }^{7}$ including cancer $^{89}$ and achondroplasia, ${ }^{10}$ and is thought to be due to the age associated increase in sporadic de novo mutations in male germ cells. ${ }^{11}$

One study estimated that about a quarter $(26.6 \%)$ of cases of schizophrenia could be attributed to paternal age. ${ }^{5}$ It has been suggested that if this association between paternal age and schizophrenia was due to accumulating de novo mutations, sporadic cases of schizophrenia should show a stronger association with increased paternal age compared with cases in people with a known family history of the disorder. ${ }^{12}$ However, studies to date have been too small to explore fully interactions with other risk factors or have not fully assessed the range of confounding factors that may contribute to the observed associations. ${ }^{136}$

Using a large Swedish record linkage database, we investigated the association between paternal age and schizophrenia in offspring, in particular the extent to which observed associations may be confounded by birth related exposures, socioeconomic factors, family history of psychosis, and early parental death. We also investigated whether any associations differed in relation to family history, sex, birth weight, and Apgar score. We investigated the latter two because they have been identified as possible environmental risk factors, ${ }^{13}{ }^{14}$ and it has been hypothesised that in the presence of genetic predisposition, exposure to such factors may lead to the clinical manifestation of schizophrenia. $^{15} 16$

\section{Method}

\section{Sample}

Our cohort comprised 754330 people born in Sweden between 1973 and 1980 and still alive and resident in Sweden at the age of 16 years. Information on the study sample was obtained from linkage between Sweden's medical birth registry, its population and housing census of 1990, its inpatient discharge register (up to 31 December 2001), and its cause of death and emigration registers (up to 31 December 2001). We identified full siblings to index subjects from the multi-generation register.

Our analysis was based on records of people admitted to hospital between 1989-2001 with a diagnosis of schizophrenia (international classification of diseases, 10th revision, ICD-10: F20; ninth revision, ICD-9, Swedish version: all 295 except 295F and $295 \mathrm{H}$ ) or other non-affective psychosis (ICD-10: F21-29; ICD-9 Swedish version: 295F, 295H, 297-8) (see table A on bmj.com).

Overall, $42316(5.6 \%)$ people were excluded from the main analysis because of missing data for one or more of the variables examined (including 93 with schizophrenia and 130 with non-schizophrenic non-affective psychosis) or because they developed schizophrenia (68 cases) or other non-affective psychosis (141 cases) before the age of 16 years. Average paternal age was higher in those excluded because of missing data (31.0 $v 29.8$ years, $\mathrm{P}<0.0001$ ). Our analyses are therefore based on 712014 subjects from 532761 distinct families. Only four of the 639 people with schizophrenia and seven of the 1311 with non-schizophrenic non-affective psychosis were siblings.

\section{Variables examined}

We coded paternal age as <21, 21-24, 25-29, 30-34, 35-39, $40-44,45-49$, and $\geq 50$ years. We examined the influence of seven possible confounding factors on the associations with paternal age.

- Sex

- The subject's age on 31 December 2001 to control for calendar year effects

Two extra tables of data can be found on bmj.com 
- Maternal age (coded in five year age bands up to the age of 40 years)

- Place of birth (coded as a three level variable ${ }^{17}$ : main cities and their suburbs, large and medium sized cities, and rural or sparsely populated areas)

- Obstetric complications and measures of fetal growth (birth weight, birth length, gestational age, season of birth, caesarean section, parity, Apgar score at one and five minutes (five minute scores were not recorded for $22.4 \%$; for our analyses we assumed that all these had five minute scores of $>6$ ))

- Family history of schizophrenia or non-schizophrenic non-affective psychosis. We coded any person with a mother, father, or full sibling admitted to hospital between 1964 and 2001 with a diagnosis of schizophrenia as having a family history of schizophrenia. For analysis of associations with nonschizophrenic non-affective psychosis our definition of a family history included people with parents or siblings with any non-affective psychosis. (See table A on bmj.com.) As the Swedish register of psychiatric inpatients did not achieve full national coverage until 1987 we probably missed some individuals with a family history

- Childhood socioeconomic position (three measures derived from the Swedish population and housing census 1990: highest annual income of either parent $(<\mathrm{Kr} 100000$ (£7467, \$13 328, $€ 10$ 953), Kr100 001-200 000, Kr200 001-300 000, $>$ Kr300 000); highest socioeconomic index of either parent (blue collar worker, white collar worker, self employed, and other); and highest educational level of either parent $(<9$ years of education, 9-10 years of education, full secondary education, higher education).

\section{Data analysis}

All statistical analysis was performed with Stata Release 8.0 (StataCorp, College Station, TX). We used Cox's proportional hazards models to assess the influence of paternal age on psychosis. People were censored at the time of first admission for schizophrenia, non-schizophrenic non-affective psychosis, death, or emigration. We used the cluster option in Stata to adjust standard errors for clustering of cases within families. We controlled all reported hazard ratios for sex, age, and maternal age, unless otherwise specified or stratified by sex. We tested the validity of the proportional hazards assumption graphically and used Wald tests to investigate interaction effects.

\section{Results}

\section{Parental age}

Subjects were followed up for a mean of nine years after the age of 16 years. During this follow up period $639(0.09 \%)$ were admitted with a diagnosis of schizophrenia and $1311(0.18 \%)$ with a diagnosis of non-affective non-schizophrenic psychosis. The estimated annual incidence rates were 0.10 and 0.21 per 1000 person years, respectively.

Table 1 shows the characteristics of subjects in relation to the age of their father. People with older fathers tended also to have older mothers and mothers who had had more pregnancies. People with older fathers were more likely to lose their parents before they reached the age of 18 years; they were more likely to have a family history of psychosis; and their parents were more likely to come from extreme ends of the distribution of the various measures of socioeconomic position.

Table 2 shows the hazard ratios for successive five year paternal age groups. In the basic model, adjusted for sex, age, and maternal age, there is a clear increase in the risk of schizophrenia with increasing paternal age. There is a suggestion that the
Table 1 Characteristics of subjects according to paternal age groups. Figures are number (percentage) unless stated otherwise

\begin{tabular}{|c|c|c|c|}
\hline & $<30$ years & $30-39$ years & $\geq 40$ years \\
\hline Total & $374783(52.6)$ & 299707 (42.1) & 37524 (5.3) \\
\hline Schizophrenia & $291(0.08)$ & $297(0.10)$ & $51(0.14)$ \\
\hline $\begin{array}{l}\text { Non-schizophrenia } \\
\text { non-affective } \\
\text { psychosis }\end{array}$ & $652(0.17)$ & $572(0.19)$ & $87(0.23)$ \\
\hline Male & $192411(51.3)$ & $153794(51.3)$ & $19138(51.0)$ \\
\hline $\begin{array}{l}\text { Mean maternal age (SD) } \\
\text { at birth (years) }\end{array}$ & $24.30(3.48)$ & $29.70(3.83)$ & $34.26(4.89)$ \\
\hline $\begin{array}{l}\text { Mean (SD) birth weight } \\
(\mathrm{g})\end{array}$ & 3475 (525) & 3525 (541) & 3519 (568) \\
\hline $\begin{array}{l}\text { Mean (SD) gestational } \\
\text { age (weeks) }\end{array}$ & $39.8(1.8)$ & $39.7(1.8)$ & $39.5(1.8)$ \\
\hline \multicolumn{4}{|l|}{ Season of birth: } \\
\hline Winter & $88804(23.7)$ & $69883(23.3)$ & $8990(24.0)$ \\
\hline Spring & $107170(28.6)$ & $86852(29.0)$ & $10203(27.2)$ \\
\hline Summer & $94195(25.1)$ & $73791(24.6)$ & $9336(24.9)$ \\
\hline Autumn & $84614(22.6)$ & $69181(23.1)$ & 8995 (24.0) \\
\hline \multicolumn{4}{|l|}{ Place of birth: } \\
\hline $\begin{array}{l}\text { Main cities and } \\
\text { suburbs }\end{array}$ & $97662(26.1)$ & $89858(30.0)$ & $11208(29.9)$ \\
\hline $\begin{array}{l}\text { Large cities and } \\
\text { industry }\end{array}$ & 237286 (63.3) & $177743(59.3)$ & $21389(57.0)$ \\
\hline Rural areas & $39835(10.6)$ & $32106(10.7)$ & 4927 (13.1) \\
\hline $\begin{array}{l}\text { Apgar score } \leq 6 \text { at one } \\
\text { minute }\end{array}$ & $15407(4.1)$ & $11028(3.7)$ & $1563(4.2)$ \\
\hline \multicolumn{4}{|l|}{ Parity of mother: } \\
\hline 1 & $213752(57.0)$ & 83645 (27.9) & $9246(24.6)$ \\
\hline 2 & $130110(34.7)$ & 129786 (43.3) & $11357(30.3)$ \\
\hline$\geq 3$ & $30921(8.3)$ & $86276(28.8)$ & $16921(45.1)$ \\
\hline Twin or multiple birth & $5320(1.4)$ & $5294(1.8)$ & $754(2.0)$ \\
\hline $\begin{array}{l}\text { Parent or sibling } \\
\text { admitted with } \\
\text { schizophrenia }\end{array}$ & $1670(0.5)$ & $1527(0.5)$ & $312(0.8)$ \\
\hline $\begin{array}{l}\text { Parent or sibling } \\
\text { admitted with } \\
\text { schizophrenia or } \\
\text { non-affective } \\
\text { non-schizophrenic } \\
\text { psychosis }\end{array}$ & $6350(1.7)$ & $5909(2.0)$ & $1120(3.0)$ \\
\hline $\begin{array}{l}\text { Father died before } \\
\text { subject was aged } 18\end{array}$ & $5706(1.5)$ & $6968(2.3)$ & $2984(8.0)$ \\
\hline $\begin{array}{l}\text { Mother died before } \\
\text { subject was aged } 18\end{array}$ & $2665(0.7)$ & 3391 (1.1) & $639(1.7)$ \\
\hline \multicolumn{4}{|c|}{ Highest parental annual income*: } \\
\hline$<$ Kr100 000 & $18720(5.0)$ & $13532(4.5)$ & $4199(11.2)$ \\
\hline Kr100 001-200 000 & $206525(55.1)$ & $140371(46.8)$ & $20220(51.6)$ \\
\hline Kr200 001-300 000 & $116983(31.2)$ & $103040(34.4)$ & $9815(32.3)$ \\
\hline$>\mathrm{Kr} 300000$ & $32555(8.7)$ & $42764(14.3)$ & $3290(11.0)$ \\
\hline \multicolumn{4}{|c|}{ Highest parental socioeconomic status: } \\
\hline Blue collar & $123963(33.1)$ & $72635(24.2)$ & $12404(33.1)$ \\
\hline White collar & $204793(54.6)$ & $187219(62.5)$ & $19175(51.1)$ \\
\hline Self employed & 42409 (11.3) & $37514(12.5)$ & $5304(14.1)$ \\
\hline Other & $3618(1.0)$ & $2339(0.8)$ & $641(1.7)$ \\
\hline \multicolumn{4}{|l|}{ Highest parental education: } \\
\hline$<9$ years & $15433(4.1)$ & $31411(10.5)$ & $8641(23.0)$ \\
\hline $9-10$ years & $54461(14.5)$ & $32649(10.9)$ & $3889(10.4)$ \\
\hline Full secondary school & $187186(50.0)$ & $110398(36.8)$ & $12150(32.4)$ \\
\hline Higher & $117703(31.4)$ & $125249(41.8)$ & $12844(34.2)$ \\
\hline
\end{tabular}

${ }^{*} \mathrm{Kr} 100000=£ 7467, \$ 13238, € 10953$.

offspring of younger fathers ( $<21$ years) are also at somewhat greater risk than those with fathers aged 21-24 years (hazard ratio $1.34,95 \%$ confidence interval 0.74 to 2.43 ), but there was no evidence of a non-linear association between paternal age and schizophrenia ( $\mathrm{P}=0.39$, quadratic). The strength of the association between paternal age and schizophrenia changed hardly at all when we also controlled for risk factors related to 
Table 2 Hazard ratios (with 95\% confidence intervals) of schizophrenia in relation to paternal age ( $\mathrm{n}=639$ cases of schizophrenia)

\begin{tabular}{|c|c|c|c|c|c|}
\hline & No of cases & $\begin{array}{l}\text { Model 1: controlled for sex, } \\
\text { age, and maternal age }\end{array}$ & $\begin{array}{l}\text { Model 2: as model } 1 \text { plus birth } \\
\text { related factors* }\end{array}$ & $\begin{array}{l}\text { Model 3: as model } 2 \text { plus } \\
\text { parental death and family } \\
\text { history of schizophrenia }\end{array}$ & $\begin{array}{l}\text { Model 4: as model } 3 \text { plus } \\
\text { socioeconomic variablest }\end{array}$ \\
\hline \multicolumn{6}{|l|}{ Paternal age groups (years): } \\
\hline$<21$ & 15 & 1.34 (0.75 to 2.43$)$ & 1.33 (0.73 to 2.39$)$ & 1.33 (0.74 to 2.40 ) & 1.31 (0.73 to 2.36 ) \\
\hline $21-24$ & 72 & 1.00 & 1.00 & 1.00 & 1.00 \\
\hline $25-29$ & 204 & 1.22 (0.91 to 1.64$)$ & 1.24 (0.92 to 1.68$)$ & 1.25 (0.93 to 1.68$)$ & $1.26(0.93$ to 1.69$)$ \\
\hline $30-34$ & 194 & 1.62 (1.15 to 2.28$)$ & 1.67 (1.19 to 2.36$)$ & 1.66 (1.18 to 2.34 ) & 1.66 (1.18 to 2.34$)$ \\
\hline $35-39$ & 103 & 2.33 (1.57 to 3.46 ) & 2.42 (1.62 to 3.60$)$ & 2.37 (1.60 to 3.53 ) & 2.32 (1.56 to 3.44$)$ \\
\hline $40-44$ & 32 & 2.23 (1.33 to 3.73$)$ & 2.30 (1.38 to 3.85$)$ & 2.22 (1.33 to 3.71$)$ & $2.08(1.25$ to 3.46$)$ \\
\hline $45-49$ & 7 & 1.50 (0.64 to 3.47$)$ & 1.53 (0.66 to 3.56$)$ & 1.47 (0.63 to 3.41$)$ & 1.30 (0.56 to 3.06 ) \\
\hline$\geq 50$ & 12 & 5.85 (2.91 to 11.74$)$ & 5.85 (2.92 to 11.73$)$ & 5.46 (2.68 to 11.11$)$ & $4.62(2.28$ to 9.36$)$ \\
\hline $\begin{array}{l}\text { Change per } 10 \text { year increase in } \\
\text { paternal age }\end{array}$ & - & $1.56(1.30$ to 1.88$)$ & 1.58 (1.32 to 1.89$)$ & 1.54 (1.29 to 1.85$)$ & 1.47 (1.23 to 1.76$)$ \\
\hline
\end{tabular}

${ }^{\star}$ Birth weight, birth length, gestational age, place of birth, season, Apgar score at one and five minutes, parity, multiple birth.

†Three measures from Swedish housing and population census 1990: highest annual income of either parent, highest socioeconomic index of either parent, highest educational level of either parent.

birth, parental death before the subject reached the age of 18 years, and family history of schizophrenia, though there was a modest reduction in models after we controlled for the three socioeconomic variables. The variable mostly responsible for this drop was highest annual parental income.

Table 3 shows the results for the same series of models for non-schizophrenic non-affective psychosis. Overall, we found a much weaker association. Just as with schizophrenia we found an increased risk in the offspring of younger men $(<21$ years) with some evidence for a non-linear association ( $\mathrm{P}=0.01$, quadratic).

When we combined cases of narrowly defined schizophrenia and non-schizophrenic non-affective psychosis into one category the hazard ratio associated with each 10 year increase in paternal age was 1.31 (1.17 to 1.47) when we controlled for sex, age, and maternal age and 1.23 (1.10 to 1.37 ) in the fully controlled model.

Maternal age showed a weak association with schizophrenia in the unadjusted model (hazard ratio per 10 year increase in maternal age $1.21,1.02$ to 1.43 ), but this association disappeared as soon as we controlled for paternal age, sex, and age (0.83, 0.64 to 1.07 ) (see table $\mathrm{B}$ on bmj.com). We found a similar pattern for non-schizophrenic non-affective psychosis (crude hazard ratio per 10 year increase in maternal age was 1.10 (0.98 to 1.23) and 0.94 (0.79 to 1.12) when we controlled for sex, age, and paternal age

We calculated that the population attributable fraction of schizophrenia in this sample due to having a father aged $>30$ years at birth was $15.5 \%$.

\section{Association with family history, sex, birth weight, Apgar} scores, and age of onset

Associations with paternal age differed in those with and without a family history of schizophrenia ( $\mathrm{P}=0.04$ for interaction). The hazard ratio for every 10 years of paternal age was 1.60 (1.32 to 1.92 ) in those with no family history of schizophrenia and 0.91 (0.44 to 1.89 ) in those with an affected first degree relative.

We found no strong evidence for any marked difference in the association between paternal age and schizophrenia by sex $(\mathrm{P}=0.20$, for interaction). Hazard ratios increased by 1.65 (1.32 to 2.06) for men and by 1.40 (1.03 to 1.89 ) for women for every 10 years of paternal age.

We found no evidence for any marked difference in associations in those with high and low birth weight $(\mathrm{P}=0.15$ for interaction). The association of paternal age with schizophrenia, however, differed in relation to the subjects' Apgar score at birth $(\mathrm{P}=0.02$ for interaction). In those with normal Apgar scores $(7-10)$ at one minute hazard ratios increased by 1.60 for every 10 years of paternal age (1.33 to 1.92) but not in those with Apgar scores suggestive of the need for resuscitation (hazard ratios decreased by $0.92,0.31$ to 2.76). Similar but weaker effects $(\mathrm{P}=0.16$ for interaction) were seen with Apgar scores at five minutes. We found no marked change in the strength of association between paternal age and schizophrenia when we restricted the proportional hazards model to the first or the second half of the follow up period.

Table 3 Hazard ratios (with 95\% confidence intervals) of non-schizophrenic non-affective psychosis in relation to paternal age ( $\mathrm{n}=1311$ cases of non-schizophrenic, non-affective psychosis)

\begin{tabular}{|c|c|c|c|c|c|}
\hline & No of cases & $\begin{array}{l}\text { Model 1: controlled for sex, } \\
\text { age, and maternal age }\end{array}$ & $\begin{array}{l}\text { Model 2: as model } 1 \text { plus birth } \\
\text { related factors* }\end{array}$ & $\begin{array}{l}\text { Model 3: as model } 2 \text { plus } \\
\text { parental death and family } \\
\text { history of schizophrenia }\end{array}$ & $\begin{array}{l}\text { Model 4: as model } 3 \text { plus } \\
\text { socioeconomic variablest }\end{array}$ \\
\hline \multicolumn{6}{|l|}{ Paternal age groups (years): } \\
\hline$<21$ & 35 & 1.58 (1.04 to 2.41$)$ & 1.56 (1.03 to 2.37 ) & 1.57 (1.04 to 2.38 ) & 1.55 (1.02 to 2.35$)$ \\
\hline $21-24$ & 168 & 1.00 & 1.00 & 1.00 & 1.00 \\
\hline $25-29$ & 449 & 0.99 (0.82 to 1.20$)$ & 1.01 (0.83 to 1.22$)$ & 1.01 (0.83 to 1.22$)$ & 1.01 (0.83 to 1.22$)$ \\
\hline $30-34$ & 404 & 1.15 (0.92 to 1.44$)$ & 1.19 (0.95 to 1.49$)$ & 1.17 (0.93 to 1.46$)$ & 1.17 (0.94 to 1.46$)$ \\
\hline $35-39$ & 168 & 1.29 (0.98 to 1.69$)$ & 1.34 (1.02 to 1.77$)$ & 1.28 (0.98 to 1.68$)$ & 1.27 (0.97 to 1.66$)$ \\
\hline $40-44$ & 49 & 1.18 (0.81 to 1.73$)$ & 1.24 (0.85 to 1.81$)$ & 1.14 (0.78 to 1.66$)$ & 1.10 (0.75 to 1.60$)$ \\
\hline $45-49$ & 30 & 2.30 (1.47 to 3.59 ) & 2.37 (1.52 to 3.70$)$ & 2.15 (1.38 to 3.35$)$ & 2.00 (1.60 to 3.11$)$ \\
\hline$\geq 50$ & 8 & 1.40 (0.68 to 2.89$)$ & 1.40 (0.68 to 2.90$)$ & 1.12 (0.54 to 2.32$)$ & 1.01 (0.49 to 2.10$)$ \\
\hline $\begin{array}{l}\text { Change per } 10 \text { year increase in } \\
\text { paternal age }\end{array}$ & - & 1.19 (1.03 to 1.38$)$ & 1.22 (1.06 to 1.41$)$ & 1.15 (1.00 to 1.32$)$ & 1.12 (0.98 to 1.29$)$ \\
\hline
\end{tabular}

*Birth weight, birth length, gestational age, place of birth, season, Apgar score at one and five minutes, parity, multiple birth.

†Three measures from Swedish housing and population census 1990: highest annual income of either parent, highest socioeconomic index of either parent, highest educational level of either parent. 


\section{Discussion}

Our findings confirm an association between increased paternal age and schizophrenia in offspring, which remained even after we controlled for a wide range of potential confounding factors. The association seems to be relatively specific to schizophrenia compared with non-schizophrenic non-affective psychosis and was stronger in those with no family history of the disorder and those with normal Apgar scores at birth.

\section{Strengths and weaknesses of study}

We used routinely recorded data on variables related to birth, parents, and adulthood collected before the onset of disease. Furthermore, as cases were ascertained from a national inpatient register the possibility of selection bias was reduced. The large number of cases gives us statistical power to control for a wide range of important confounding factors and investigate whether the associations differ in relation to family history of psychosis or environmental risk factors.

The main limitation of our analysis is that case ascertainment was based on people admitted to hospital only with diagnoses recorded on an administrative database. Though we will have missed people who were not admitted to hospital, studies in the United Kingdom indicate that in the first three years after presentation over $80 \%$ of patients are admitted, even in areas with community oriented services. ${ }^{18}$ Furthermore, analyses of diagnoses recorded on the Swedish inpatient discharge register indicate that schizophrenia is diagnosed with reasonable accuracy ${ }^{19-20}$ Another limitation is that a family history of admission with schizophrenia is only a marker for and not the equivalent of genetic vulnerability.

\section{Comparison of findings with earlier research}

In comparing our findings with those of earlier studies ${ }^{1-3}{ }^{56}$ it is important to bear in mind that we were able to distinguish between narrowly defined schizophrenia (ICD-10 F20) and other non-schizophrenic non-affective psychosis (ICD-10 F2129). One previous study ${ }^{1}$ also reported a stronger association with paternal age in relation to narrowly defined schizophrenia.

We found a pattern of association across the categories of paternal age that suggested a J shaped rather than a linear association, in line with the initial unadjusted findings of Byrne et al. ${ }^{2}$ In our study this pattern remained even after we controlled for possible confounders. Two other studies also investigated the possibility of a stronger association of increased paternal age in people with schizophrenia without a family history as opposed to those with a family history, as this would provide further evidence to support the hypothesis that this association is due to accumulating de novo mutations in the germ cells of older fathers. Malaspina et al showed that paternal age was significantly higher for people with schizophrenia without a family history in a small study that compared 35 familial cases with 68 sporadic cases. ${ }^{12}$ Zammit et al found no evidence for such effects, but their study lacked statistical power. ${ }^{6}$

The finding that the association between increased paternal age and schizophrenia was evident only in people with normal Apgar scores was based on a relatively small number of cases in people with low scores $(\mathrm{n}=31)$ and should be viewed as preliminary until replicated in other studies.

\section{Conclusions}

Our findings confirm advancing paternal age as a strong independent risk factor for schizophrenia and indicate that $15.5 \%$ of cases of schizophrenia in our cohort could be due to the patient having a father who was aged $>30$ years at birth. We

\section{What is already known on this topic}

Increased paternal age is associated with several diseases, possibly due to the age associated increase in sporadic de novo mutations in male germ cells

Several studies have reported an association between paternal age at conception and their offspring's risk of schizophrenia

If this association was due to de novo mutations one would expect to find a stronger association between paternal age and schizophrenia in cases with no family history of the disorder

\section{What this study adds}

There is a strong positive association between paternal age and schizophrenia that is not due to sociodemographic, birth related, or socioeconomic factors or family history or early parental death

Paternal age is only weakly associated with other non-affective, non-schizophrenic psychosis

This association is stronger in those with no family history of schizophrenia, supporting the hypothesis that accumulating de novo mutations in the germ lines of older fathers could play an important part in the aetiology of schizophrenia

found a stronger association in subjects without a family history of schizophrenia, providing further evidence to support the theory that accumulating de novo mutations in the germ cells of older fathers might contribute to an increased risk of schizophrenia in their offspring.

In England and Wales the average paternal age has increased from 29.2 years in 1980 to 32.1 in $2002 .{ }^{21}$ Using our data we can estimate the hazard ratio associated with an average increase of paternal age by 2.9 years as 1.12 . Assuming a conservative background annual incidence rate for schizophrenia of $10 / 100000^{22}$ for the whole of the UK population (59.2 million in 2002) and that the observed associations are truly causal, this increase in paternal age since 1980 could have led to an additional 710 cases of schizophrenia in 2002 over and above the 5923 cases due to the background incidence rate.

We thank Christina Dalman, Peter Allebeck, and Susanne Wicks for their helpful comments, Stan Zammit for his help with accessing all the relevant literature, and Geoff Adams for statistical/database support.

Contributors: DG, FR, and GH developed the core idea, and FR, AS, DG, GH, GL, DAL, and PT were involved in the design of the study. DG, FR, GH, GL, and DAL raised the research funds. PT prepared the cohort data and did the database linkages. AS carried out the statistical analysis and literature search and wrote the first draft of the paper. DG, DAL, and GL gave advice on statistical methodology. All authors critically reviewed and contributed to the final draft of the paper. FR and AS are guarantors.

Funding: Stanley Medical Research Institute.

Competing interests: None declared.

Ethical approval: The ethics committee at the Karolinska Institute, Stockholm, Sweden approved this study.

1 Brown AS, Schaefer CA, Wyatt RJ, Begg MD, Goetz R, Bresnahan MA, et al. Paternal age and risk of schizophrenia in adult offspring. Am J Psychiatry 2002;159:1528-33.

Byrne M, Agerbo E, Ewald H, Eaton WW, Mortensen PB. Parental age and risk of Byrne M, Agerbo E, Ewald H, Eaton WW, Mortensen PB. Parental a
schizophrenia: a case-control study. Arch Gen Psychiatry 2003;60:673-8.

3 Dalman C, Allebeck P. Paternal age and schizophrenia: further support for an association. Am J Psychiatry 2002;159:1591-2. 
4 El Saadi O, Pedersen CB, McNeil TF, Saha S, Welham J, O'Callaghan E, et al. Paternal and maternal age as risk factors for psychosis: findings from Denmark, Sweden and Australia. Schizophr Res 2004;67:227-36.

5 Malaspina D, Harlap S, Fennig S, Heiman D, Nahon D, Feldman D, et al. Advancing paternal age and the risk of schizophrenia. Arch Gen Psychiatry 2001;58:361-7.

6 Zammit S, Allebeck P, Dalman C, Lundberg I, Hemmingson T, Owen MJ, et al. Paternal age and risk for schizophrenia. Br J Psychiatry 2003;183:405-8.

7 Crow JF. The high spontaneous mutation rate: is it a health risk? Proc Natl Acad Sci U S A 1997;94:8380-6.

8 Zhang Y, Kreger BE, Dorgan JF, Cupples LA, Myers RH, Splansky GL, et al. Parental age at child's birth and son's risk of prostate cancer. The Framingham study. Am J Epidemiol 1999:150:1208-12.

9 Hemminki K, Kyyronen P. Parental age and risk of sporadic and familial cancer in offspring: implications for germ cell mutagenesis. Epidemiology 1999;10:747-51.

10 Wilkin DJ, Szabo JK, Cameron R, Henderson S, Bellus GA, Mack ML, et al. Mutations in fibroblast growth-factor receptor 3 in sporadic cases of achondroplasia occur exclusively on the paternally derived chromosome. Am J Hum Genet 1998;63:711-6.

11 Crow JF. Development. There's something curious about paternal-age effects. Science 2003;301:606-7.

12 Malaspina D, Corcoran C, Fahim C, Berman A, Harkavy-Friedman J, Yale S, et al. Paternal age and sporadic schizophrenia: evidence for de novo mutations. Am J Med Genet 2002;114:299-303.

13 Dalman C, Thomas HV, David AS, Gentz J, Lewis G, Allebeck P. Signs of asphyxia at birth and risk of schizophrenia. Population-based case-control study. Br J Psychiatry 2001;179:403-8.

14 Gunnell D, Rasmussen F, Fouskakis D, Tynelius P, Harrison G. Patterns of fetal and childhood growth and the development of psychosis in young males: a cohort study. Am J Epidemiol 2003;158:291-300

15 Pearlson GD. Neurobiology of schizophrenia. Ann Neurol 2000;48:556-66

16 Velakoulis D, Wood SJ, McGorry PD, Pantelis C. Evidence for progression of brain structural abnormalities in schizophrenia: beyond the neurodevelopmental model. Aust N Z J Psychiatry 2000;34 suppl:S113-26.

17 Harrison G, Fouskakis D, Rasmussen F, Tynelius P, Sipos A, Gunnell D. Association between psychotic disorder and urban place of birth is not mediated by obstetric complications or childhood socio-economic position: a cohort study. Psychol Med 2003;33:723-31.
18 Sipos A, Harrison G, Gunnell D, Amin S, Singh SP. Patterns and predictors of hospitalisation in first-episode psychosis. Prospective cohort study. $\mathrm{Br} J$ Psychiatry 2001;178:518-23.

19 Dalman C, Broms J, Cullberg J, Allebeck P. Young cases of schizophrenia identified in a national inpatient register-are the diagnoses valid? Soc Psychiatry Psychiatr Epidemiol 2002;37:527-31

20 David AS, Malmberg A, Brandt L, Allebeck P, Lewis G. IQ and risk for schizophrenia: a population-based cohort study. Psychol Med 1997;27:1311-23.

21 Office of National Statistics. Birth statistics: review of the registrar general on births and fam ily building patterns in England and Wales-FM1. London: Stationery Office, 2002.

22 Brewin J, Cantwell R, Dalkin T, Fox R, Medley I, Glazebrook C, et al. Incidence of schizophrenia in Nottingham. A comparison of two cohorts, 1978-80 and 1992-94. Br J Psychiatry 1997;171:140-4.

(Accepted 4 August 2004)

doi $10.1136 /$ bmj.38243.672396.55

Academic Unit of Psychiatry, Cotham House, University of Bristol BS6 6JL Attila Sipos honorary senior clinical lecturer in psychiatry

Glynn Harrison professor of mental health

Glyn Lewis professor of psychiatric epidemiology

Department of Public Health Sciences, Karolinska Institute, Norrbacka, SE-17176 Stockholm, Sweden

Finn Rasmussen senior clinical lecturer and associate professor of epidemiology Per Tynelius senior statistician

Department of Epidemiology and Population Health, London School of Hygiene and Tropical Medicine, London WC1E 7HT

David A Leon professor of epidemiology

Department of Social Medicine, Canynge Hall, Bristol BS8 2PR

David Gunnell professor of epidemiology

Correspondence to: F Rasmussen finn.rasmussen@phs.ki.se 